Research Journal of Applied Sciences, Engineering and Technology 7(2): 311-315, 2014

DOI:10.19026/rjaset.7.256

ISSN: 2040-7459; e-ISSN: 2040-7467

(C) 2014 Maxwell Scientific Publication Corp.

Submitted: April 11, 2013

Accepted: April 22, 2013

Published: January 10, 2014

\title{
Research Article Experimental Investigation on Creep Deformation Behavior of Medium-strength Marble Rock
}

\author{
Li Yong, Zhu Weishen and Li Shucai \\ Geotechnical and Structural Engineering Research Center, Shandong University, Ji'nan 250061, China
}

\begin{abstract}
The creep deformation behavior of rocks has significant effect on the stability of underground structures. This study presents the short-term and creep deformation behavior of medium-strength marble rock using a conventional uniaxial compression testing machine and a servo-controlled rheology testing machine. The uniaxial compressive strength is obtained by the uniaxial compression testing machine. During the creep behavior test, two types of rock specimens (dry and water-saturated) are specified to be used to perform the uniaxial creep tests. Two rheological failure modes and the relationship curves between axial/circumferential strain and stress levels of marble specimens are also obtained from the creep test results. Eventually, the creep deformation behaviors are compared with those of typical soft rocks. These creep curves combined with a given creep constitutive model would provide accurate parameters for long-term stability analyses of actual projects.
\end{abstract}

Keywords: Creep deformation behavior, experimental investigation, marble rock, uniaxial creep test

\section{INTRODUCTION}

Time-dependent effects or creep deformation behavior of rocks has great importance in further development of knowledge in the field of rock mechanics. In order to study the long-term stability of the underground structures and designing their support system, time dependent deformation behavior should be highly considered (Nadimi et al., 2011). In the previous research on the creep behavior of rocks, soft rocks were excessively emphasized just like rock salt (Yang et al., 1999), argillaceous rocks (Fabre and Pellet, 2006), clays tone (Boidy et al., 2002), sandstone (Yang and Jiang, 2010) and so on. Few researchers report the creep behaviors of medium-strength rocks and hard rocks, but actually, their creep behaviors are of real existence. From newly completed underground caverns in the hydropower station in the southwest of China, the deformation of some critical points in the surrounding rock mass still increases one year after the completion of the project and has kind of tendency of no convergence. And furthermore, this kind of time-effect deformation has eventually resulted in the invalidation of some rock bolts (Zhu et al., 2011). It is apparently predicted that it would have great impacts on the overall stability of the underground structures. As we know, more than twenty large-scale underground structures will be embedded in medium-strength rocks or hard rocks; therefore, the creep behavior of them should be paid more attentions.

This study presents the experimental investigation on creep behavior of medium-strength marble rock. The medium strength represents that the uniaxial compressive strength of tested specimens is approximately 40 to $60 \mathrm{MPa}$. This kind of rock specimens is derived from the surrounding rock mass of underground caverns in Jinping I Hydropower Station. It mainly consists of carbonate minerals. It can be divided into fine-grained and medium grained marble. The grain diameter for fine-grained marble is approximately 0.5 to $1 \mathrm{~mm}$ and 1.0 to $4.0 \mathrm{~mm}$ for the medium grained. The density of marble specimens is approximately $27.0 \mathrm{~kg} / \mathrm{m}^{3}$. The diameter and height ISRM suggested of rock specimen is $50 \mathrm{~mm}$ and 100 $\mathrm{mm}$, respectively. To guarantee the homogeneousness of specimens, we use sonic apparatus to test the $\mathrm{P}$ wave's velocity $\left(V_{p}\right)$. The $V_{p}$ of selected specimens is approximately 3200 to $3800 \mathrm{~m} / \mathrm{s}$. Figure 1 shows the macroscopic structure of one selected marble specimen.

\section{EXPERIMETAL INVESTIGATION OF THE MEDIUM-STRENGTH MARBLE ROCK}

The short-term mechanical behavior of marble rock: Using the servo-controlled testing machine developed by Geotechnical and Structural Engineering Research Center, Shandong University, uniaxial compressive experiments are performed on the marble specimens. Partial specimens are shown in Fig. 2 and the servo-controlled rigid testing machine is shown in Fig. 3.

The whole loading is controlled by the longitudinal displacement velocity that is $0.002 \mathrm{~mm} / \mathrm{s}$. The stress-

Corresponding Author: Li Yong, Geotechnical and Structural Engineering Research Center, Shandong University, Ji'nan 250061, China

This work is licensed under a Creative Commons Attribution 4.0 International License (URL: http://creativecommons.org/licenses/by/4.0/). 


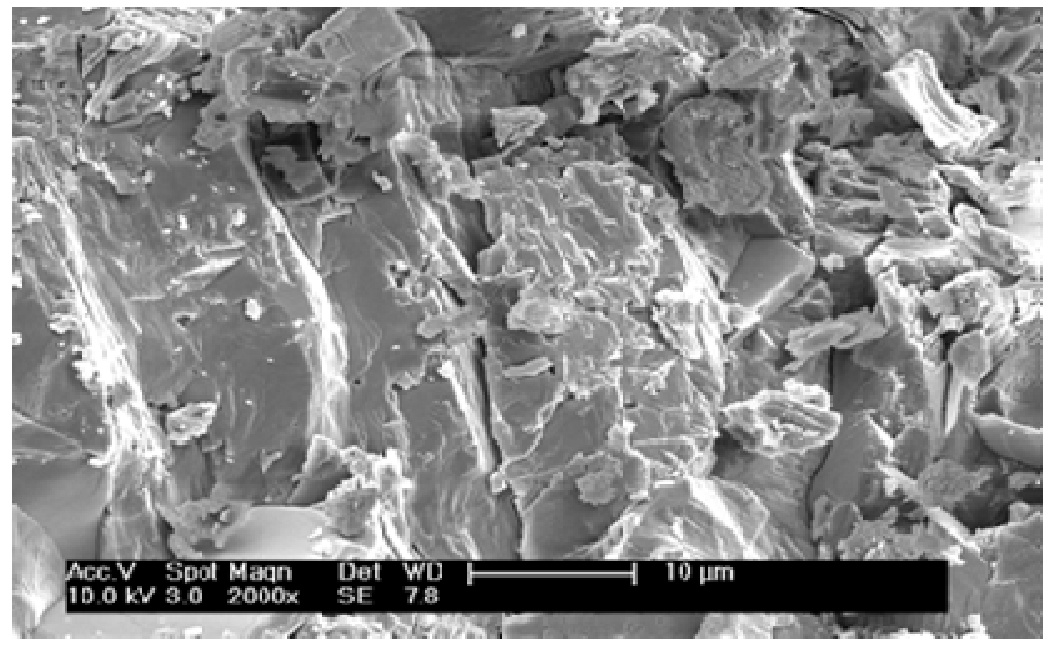

Fig. 1: Sketch figure on macroscopic structure of marble

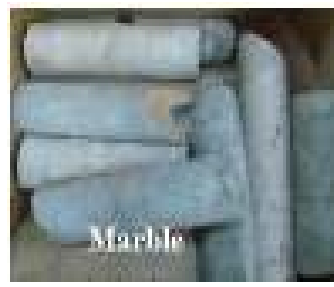

Fig. 2: Partial rock specimens

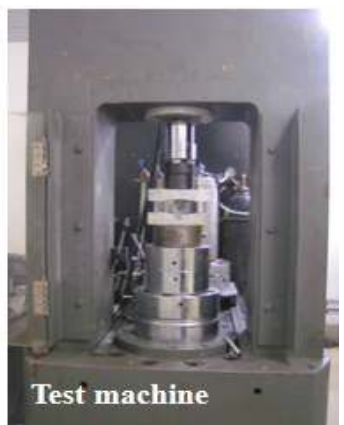

Fig. 3: A rigid compressive test machine

strain curves are automatically obtained by the experimental data collecting system. We can easily obtain some physico-mechanical parameters like elastic modulus, uniaxial compressive strength, Poisson's ratio and so on. Figure 4 shows the complete stress-strain curve of a typical marble specimen.

We can know from Fig. 4 that the uniaxial compressive strength is approximately $50 \mathrm{MPa}$. Compared with the high compressive strength up to more than $100 \mathrm{MPa}$, we determine this kind of marble rock is medium-strength marble rock. This kind of medium-strength marble rock is quite common in the hydropower stations in the southwest of China.

The creep mechanical behavior of marble rock: As the creep mechanical behavior is one of the most

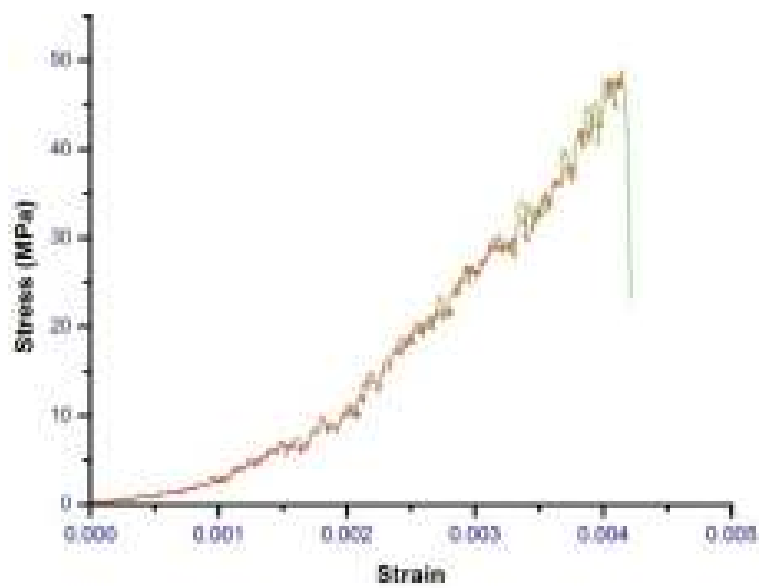

Fig. 4: The complete stress-strain curve of a marble specimen under uniaxial compression

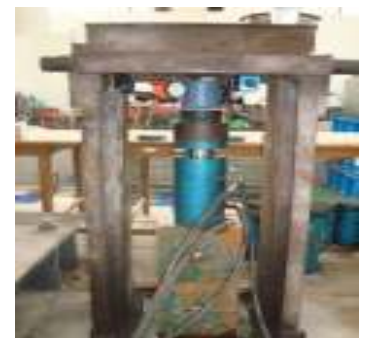

Fig. 5: A test apparatus for uniaxial compressive creep test

important mechanical characteristics, it is closely related to the long-term stability of rock engineering. The laboratory test is a significant tool to study the creep mechanical behavior and meantime, it is also a foundation to establish a time-dependent constitutive model for rock masses. The laboratory and in-situ tests are both used to test the creep behaviors of rock masses.

Known from previous research, the conventional creep tests include uniaxial compressive creep test, 


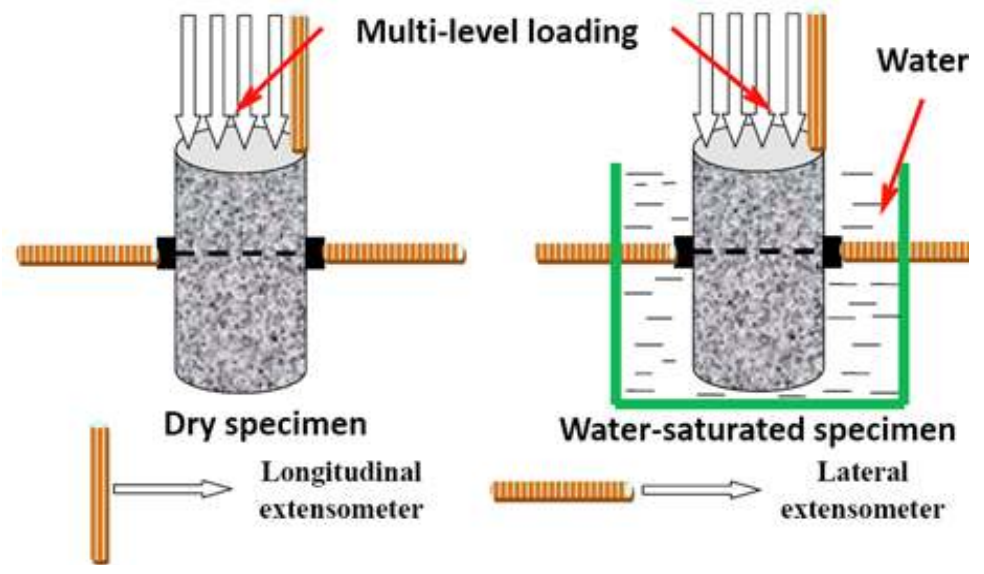

Fig. 6: A schematic diagram of uniaxial compressive creep test for dry and water-saturated specimens

direct shear creep test and triaxial compressive creep test. The previous test results are almost from soft rocks like rock salt and coal rock and the relationship between longitudinal deformation and time is overmuch highlighted but not considering the relationship between the lateral deformation and time. Almost all the specimens are totally dry in the previous study. To study the creep behaviors of medium-strength marble rock, it is necessary to perform the uniaxial creep tests on dry and water-saturated rock specimens.

The creep test requires that the applied loads should keep constant. Therefore, the creep test apparatus should have a servo-control and pressure stabilizing system and an accurate stress and deformation measuring system. We invented a simple apparatus for the uniaxial creep test which is shown in Fig. 5 the whole tests are performed in the Geotechnical Engineering Laboratory which can provide a steady room temperature and humidity.

\section{EXPERIMENTAL RESULTS AND ANALYSIS}

The two common loading methods are single-level loading and multi-level loading. The multi-level loading method is carried out during the creep test. The determination of the multi-level loads is based on the uniaxial compressive strength obtained from the shortterm mechanical behavior test. The pre-compression should be carried out on all the specimens and the time duration for pre-compression can be completed within 24 hours. When we perform the next load level, the deformation can be automatically collected at the time of 5, 10, 15, $30 \mathrm{~min}, 1,2,4,8,12,16$ and $24 \mathrm{~h}$ respectively. Afterwards, we collect the data every $24 \mathrm{~h}$ until the deformation variation is less than $0.001 \mathrm{~mm} / \mathrm{d}$. Then, the next loading level can be continued. From the final test results, the uniaxial compressive creep failures often appear after 7 to 14 days. Figure 6 shows the schematic diagram of uniaxial compressive test.

A series of creep test curves are obtained when we complete all the dry and water-saturated specimens. Figure 7 shows the relationship between axial strain of

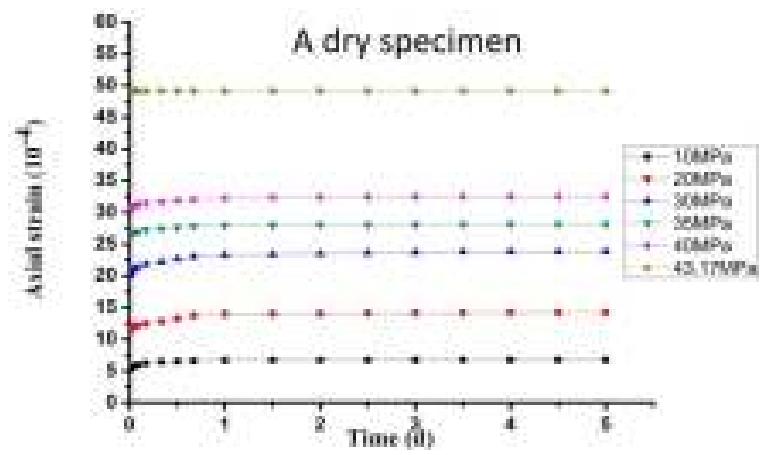

Fig. 7: Relationship between axial strain of marble and time under uniaxial compression (a dry specimen)

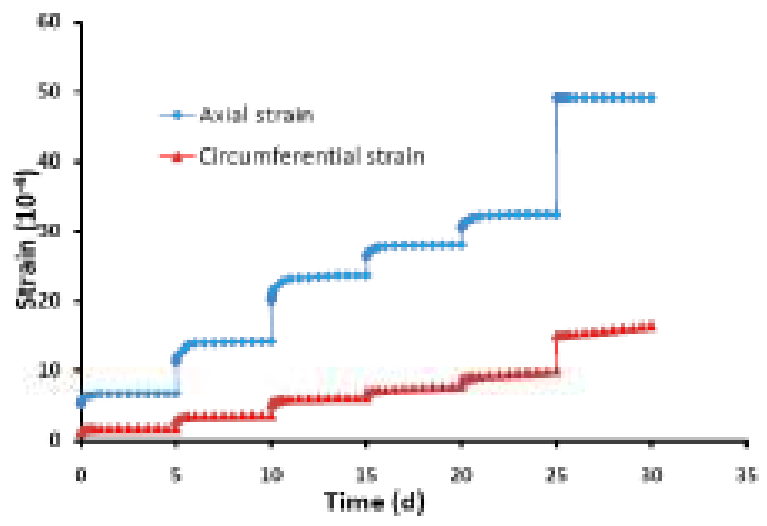

Fig. 8: Relationship between axial and circumferential strain of marble and time under uniaxial compression (a dry specimen)

dry marble specimen and time under uniaxial compression and Fig. 8 shows the relationship between axial and circumferential strain of dry marble specimen and time under uniaxial compression. Figure 9 shows the relationship between axial strain of water-saturated marble specimen and time under uniaxial compression and Fig. 10 shows the relationship between axial and circumferential strain of water-saturated marble 


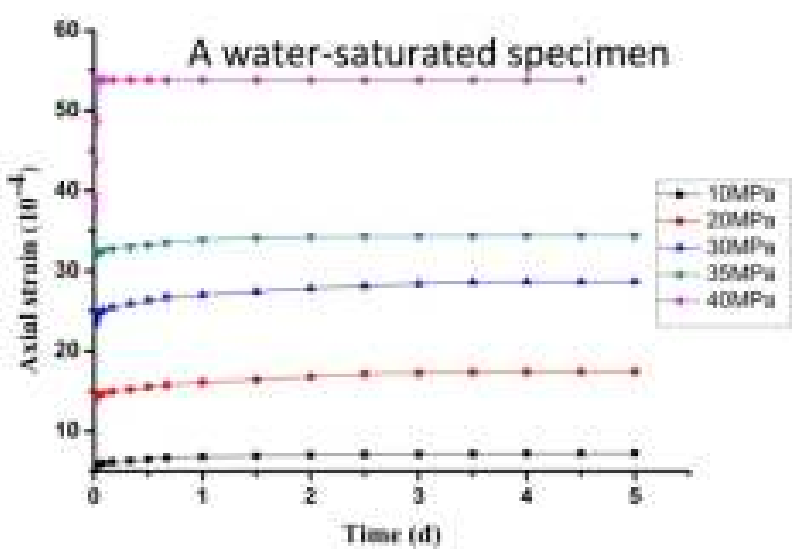

Fig. 9: Relationship between axial strain of marble and time under uniaxial compression (a water-saturated specimen)

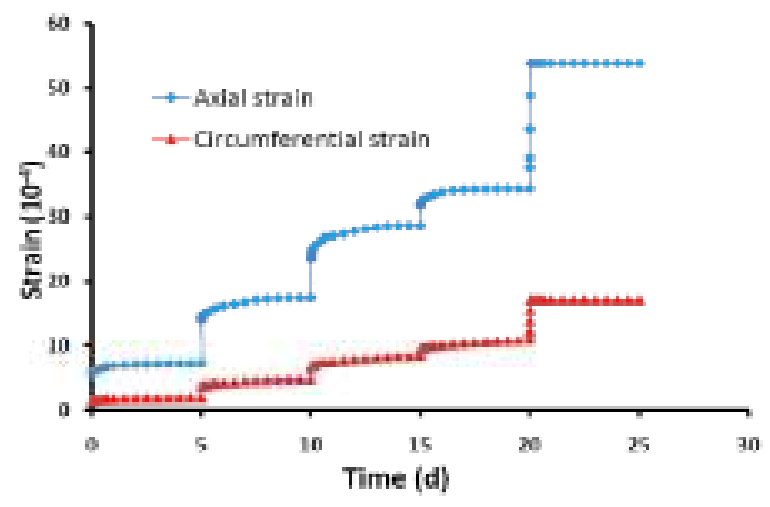

Fig. 10: Relationship between axial and circumferential strain of marble and time under uniaxial compression (a water-saturated

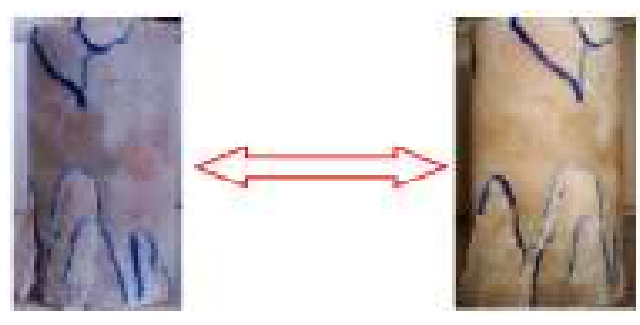

(a) Dry specimen

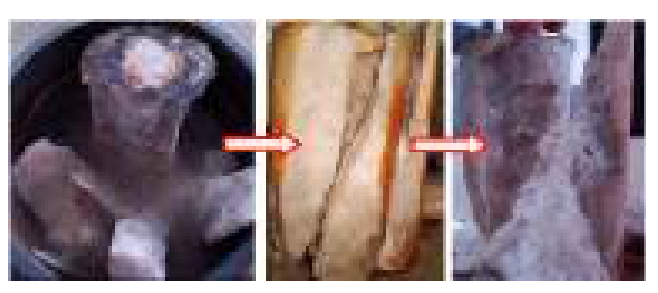

(b) Water-saturated specimen

Fig. 11: Rheological failure modes of marble specimens under uniaxial compression specimen and time under uniaxial compression. Figure 11 shows the rheological failure modes of dry and water-saturated specimens under uniaxial compression creep test.

From the creep test curves above, it can be concluded that the creep deformation behaviors and failure characteristics are obviously different from those of soft rocks. The differences are summarized as following.

- Under every loading level, the short-term deformation is approximately $70 \sim 90 \%$ of total deformation. There exists a stress threshold value for the creep of the medium-strength marble rock. The specimens appear apparent time-dependent behavior when the loading level is greater than the threshold value. This value is approximately $5 \mathrm{MPa}$ for this kind of rock.

- Under most of the loading levels, the creep deformation velocity gradually decreases as the time is growing.

- When unloading the loads to 0 , the creep deformation can almost recover to 0 as time is growing.

- The creep failures are obviously brittle failure.

- The creep failure strength for the water-saturated specimen is $40 \mathrm{MPa}$, which is $80 \%$ of the uniaxial compressive strength. But the creep failure strength for the dry specimen is $43.17 \mathrm{MPa}$, which is $86.3 \%$ of the uniaxial compressive strength.

- During the creep tests, the ratios between axial strain and circumferential strain are constantly changing. In other words, the Poisson's ratio is constantly changing during the creep tests.

\section{CONCLUSION}

A typical medium-strength marble rock derived from the surrounding rock mass of underground caverns in Jinping-I Hydropower Station is selected to perform the short-term and time-dependent mechanical behaviors test in the laboratory. The uniaxial strength and the creep test curves for the dry and water-saturated specimens are obtained during the tests. The creep curves show that the creep mechanical deformation behaviors of this medium-strength rock are totally different from those of soft rocks. These creep test results would provide some constructive suggestions for the study of long-term stability of large-scale underground caverns in southwestern China.

\section{ACKNOWLEDGMENT}

This study was financially supported by Natural Science Foundation of China (No. 51109123 and 41072234), Specialized Research Fund for the Doctoral 
Program for higher Education (No. 20110131120034) and Youth Scientist Foundation of Shandong province (Doctoral Fund, No.BS2012NJ006).

\section{REFERENCES}

Boidy, E., A. Bouvard and F. Pellet, 2002. Back analysis of time-dependent behavior of a test gallery in claystone. Tunn. Undergr. Sp. Tech., 17: 415-424.

Fabre, G. and F. Pellet, 2006. Creep and timedependent damage in argillaceous rocks. Int. J. Rock Mech. Min., 43: 950-960.

Nadimi, S., K. Shahriar, M. Sharifzadeh and P. Moarefvand, 2011. Triaxial creep tests and backanalysis of time-dependent behavior of Siah Bisheh cavern by 3-dimensional distinct element method. Tunn. Undergr. Sp. Tech., 26: 155-162.
Yang, C., J.J.K. Daemen and J.H. Yin, 1999. Experimental investigation of creep behavior of rock salt. Int. J. Rock Mech. Min., 36: 233-242.

Yang, S. and Y. Jiang, 2010. Triaxial mechanical creep behavior of sandstone. Min. Sci. Tech., 20: 339-349.

Zhu, W., Y. Li, S. Li, S. Wang and Q. Zhang, 2011. Quasi-three-dimensional physical model tests on a cavern complex under high in-situ stresses. Int. J. Rock Mech. Min., 48: 199-209. 